\title{
ALLIED HEALTH PROFESSIONALS COMPLETING A MASTER'S DEGREE IN NEUROREHABILITATION BOOST THEIR ACADEMIC CAREER AND PARTICIPATE IN CLINICAL RESEARCH PROGRAMMES
}

\author{
A. Schwarz ${ }^{1}$, M. M. Pinter ${ }^{1 *}$, Y. Teuschl' ${ }^{1}$ D. Dachenhausen ${ }^{1}$, M. Brainin ${ }^{1}$ \\ 1 Danube University Krems, Austria
}

\section{Background and aims:}

Since 2002 the Department for Clinical Neurosciences at Danube University Krems runs an interdisciplinary Master's courses in Neurorehabilitation designed specifically for allied health professionals, thereby supporting the process of academisation of physiotherapists, occupational therapists and speech therapists in German speaking countries ${ }^{1,2}$. The aim of this study was to investigate students' career choices and career development after graduation and how this affects their professional career.

\section{Method:}

An online survey was sent to 326 alumni of the Master's courses Neurorehabilitation and Neurorehabilitation Research with 37 open- and closed-ended questions on study experience and career development.

Table 1: Demographic characteristics of students studying Neurorehabilitation at Danube University Krems

\begin{tabular}{|l|c|}
\hline $\mathrm{N}$ & 124 \\
\hline Age, yr (mean \pm SD) & $43.4 \pm 9$ \\
\hline Female sex, \% & 82.3 \\
\hline Graduates, \% & 84.0 \\
\hline Class of & $2004-2014$ \\
\hline Work experience, yr (median) & 9 \\
\hline External funding, \% & 29.5 \\
\hline Professional background, \% & 6.5 \\
\hline Medical doctors & 1.6 \\
\hline Other & 91.9 \\
\hline Allied health professionals & 56.1 \\
\hline Physiotherapists & 22.0 \\
\hline Occupational therapists & 13.8 \\
\hline Speech and language therapists & \\
\hline
\end{tabular}

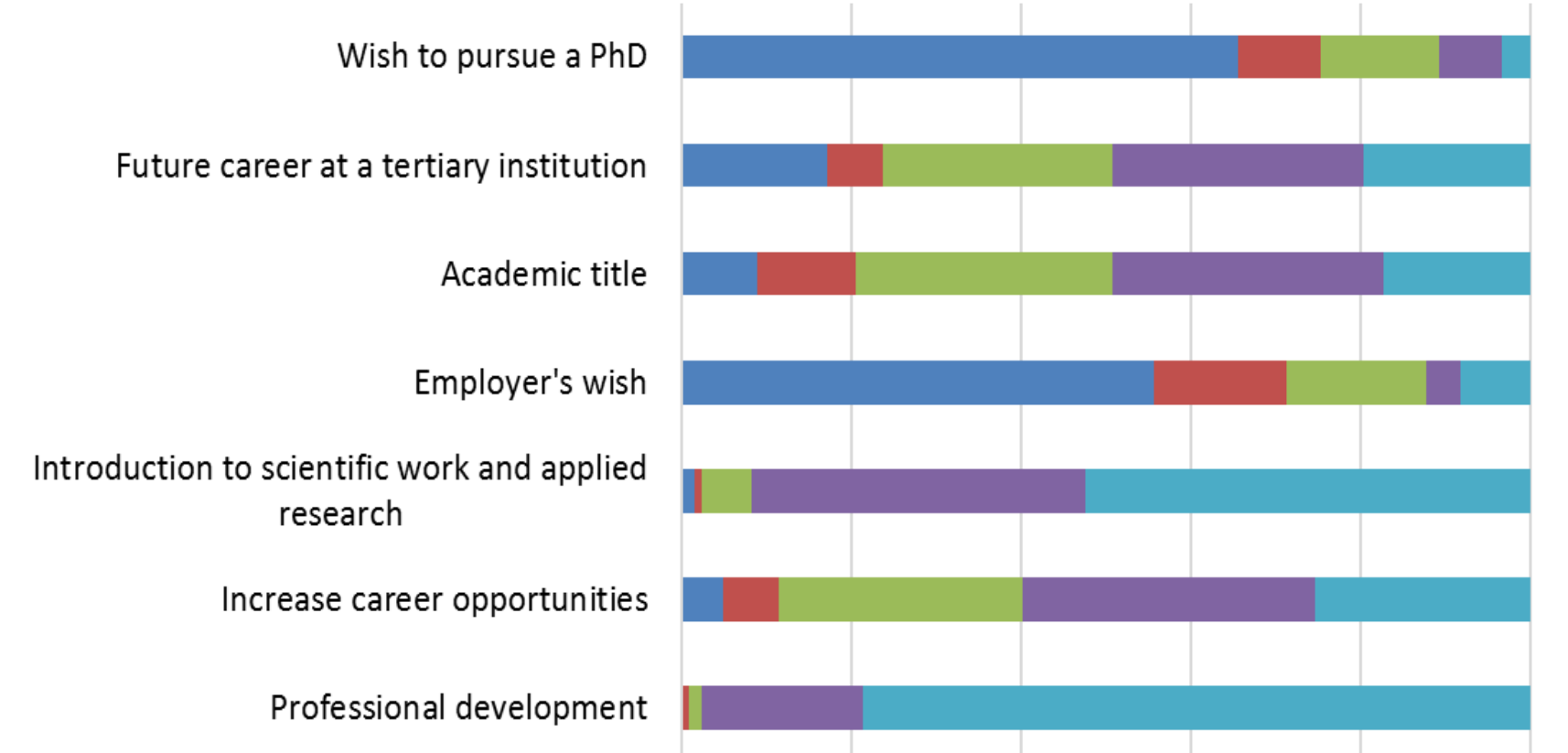

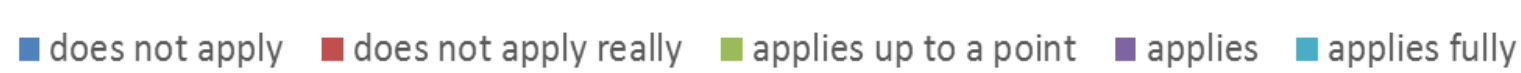

Figure 1: Reasons to pursue further education at Danube University Krems

\section{Results:}

The total response and completion rates were $38 \%(n=124)$ and $94.3 \% \quad(n=117)$, respectively. $82 \% \quad(n=102)$ of the participants were females, $18 \%(n=22)$ were males with a mean age of 43.4 years ( $\pm 9.1 \mathrm{SD}$ ) (see Table 1). Allied health professions represented in the survey were medical doctors (6.5\%) speech and language therapists (13.8\%), occupational therapists (22\%) and physiotherapists (56.1\%). Reasons for choosing a further education at Danube University Krems are illustrated in Fig. 1. Academic and personal expectations were mostly met, with a reported satisfaction rate of $73 \%$ on average. Regarding career choices and development, $16 \%(n=19)$ of survey participants reported a pay rise since graduation, $14 \%(n=17)$ now held a managing position at work, 35\% $(n=42)$ were active in teaching at universities and colleges and $12 \%(n=14)$ reported that they had become involved in part-time or fulltime research (see Fig. 2).

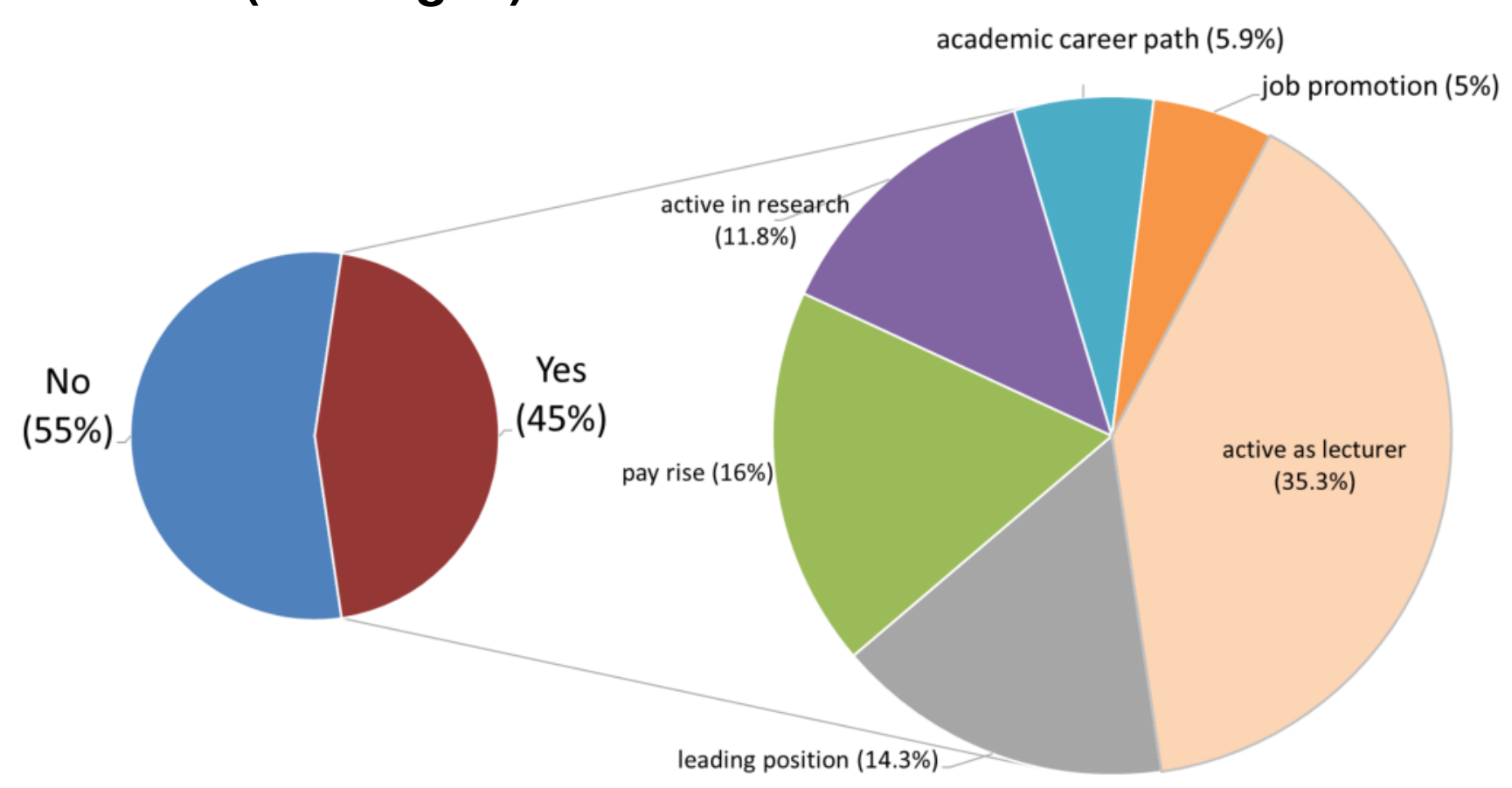

Figure 2: Reported career changes since the Master's degree in Neurorehabilitation at Danube University Krems

\section{Conclusion:}

Beyond a better understanding of evidence-based medicine and scientific methodology, the Master's courses at Danube University Krems, Austria, support students' professional development and encourage career opportunities. The academisation of allied health professionals is important and could promote new career models for this professional group.

${ }^{1} \mathrm{H}$. Höppner (Hrsg.): Promotion in den Therapiewissenschaften. 2.Auflage 2017. ISBN 978-3-86321281-0

2 A. Friedrichs, H.A. Schaub (2011): Academisation of the Health Professions- Achievements and Future Prospects. doi: 10.3205/zma000762 